\title{
A COMPARISON OF THE EFFECTIVENESS OF SUBLINGUAL MISOPROSTOL VERSUS INTRAVENOUS OXYTOCIN INFUSION IN REDUCING BLOOD LOSS IN FIRST TWO HOURS AT CAESAREAN SECTION
}

\author{
MAHHAM JANJUA, MARIA IMRAN \\ Department of Obstetrics \& Gynaecology, Lady Willingdon Hospital Lahore/ \\ King Edward Medical University, Lahore
}

\begin{abstract}
Objective: To compare the effectiveness of sublingual misoprostol in reducing intraoperative and postoperative blood loss with that of intravenous (IV) oxytocin infusion in first two hours at caesarean delivery.

Methods: It was randomized controlled trial. Study was conducted in Lady Aitchison Hospital, Lahore unit IV-King Edward Medical University and duration of study was one year. Eighty-two women with term singleton pregnancy undergone elective cesarean section under spinal anesthesia were randomly allocated to receive either misoprostol $400 \mu \mathrm{g}$ sublingually or IV infusion of 20 units oxytocin in $1000 \mathrm{ml}$ of normal saline soon after delivery of the baby. Estimated blood loss at surgery and within the first $2 \mathrm{~h}$ post-operation was measured in both groups. Side effects in both groups were also recorded.

Results: Mean blood loss with misoprostol was significantly less as compared to that of oxytocin. Post-operative hemoglobin was decreased by $-4.95 \%$ in sublingual misoprostol and in oxytocin group it was decreased by $-9.33 \%$. Blood transfusion and additional uterotonic therapy was significantly higher in oxytocin group as compared to that of misoprostol. Nausea, vomiting and hypotension was significantly higher in oxytocin group as compared to that of misoprostol group. On the other hand, pyrexia and shivering was significantly higher in misoprostol group.

Conclusion: Results of this trial showed that sublingual misoprostol is more effective as compared to intravenous oxytocin infusion in terms of reduction of blood loss in first two hours at caesarean section. It offers several advantages over oxytocin including long shelf life, stability at room temperature and oral administration which makes it suitable uterotonic agent in low-resource areas.
\end{abstract}

Key words: Caesarean delivery, Intra-operative, Postoperative, Blood loss, Sublingual misoprostol, IV oxytocin infusion, Complications, operative time, Blood transfusion

How to cite this article: Janjua M, Imran M. A comparison of the effectiveness of sublingual misoprostol versus intravenous oxytocin infusion in reducing blood loss in first two hours at caesarean section. Pak Postgrad Med J 2020;30(4): 132-137

This is an Open Access article distributed under the terms of the Creative Commons Attribution License (http://creativecommons.org/licenses/by/3.0), which permits unrestricted use, distribution, and reproduction in any medium, provided the original work is properly cited.

DOI: https://doi.org/10.51642/ppmj.v31i03.350

Correspondence to: Maria Imran,

Lady Willingdon Hospital Lahore/King Edward Medical

University, Lahore, Pakistan.

Email: drmariaimran311@gmail.com

\section{INTRODUCTION}

One of the leading cause of maternal death is postpartum hemorrhage. Its incidence varies from 5-10\% and 100 times more in under-resourced countries ${ }^{1}$. According to WHO 20 million morbidities worldwide are result of consequences of post-partum hemorrhage (PPH) and responsible for one third of maternal mortality. ${ }^{1}$ Uterine atony accounts for $70 \%$ of primary PPH and many medical and surgical interventions are used to prevent and treat it. $^{2}$ Oxytocic agents used to prevent $\mathrm{PPH}$ are oxytocin, ergot alkaloids, ergonovine (ergometrine), methylergonovine, syntometrine (5IU oxytocin $+0.5 \mathrm{mg}$ ergometrine) and prostaglandins. ${ }^{3-5}$ Surgical interventions includes surgical compression sutures, selective arterial embolization, external aortic compression, intrauterine packs, non- pneumatic anti shock garments, recently recombinant activated factor VII. ${ }^{6-10}$

Though most obstetrician use IV oxytocin as a bolus or infusion to decrease blood loss during caesarean 
section but it was seen that $10-42 \%$ females required additional uterotonic agents like ergot alkaloids or Prostaglandin (PG). ${ }^{11}$

Oxytocin is an injectable uterotonic, unstable at high temperature, require proper storage facilities, cold chain transport and have side effects like tachycardia, hypotension, nausea, vomiting, negative inotropic, antiplatelet, antidiuretic effects, and require trained birth attendants for its administration. ${ }^{3}$ Misoprostol is PGE1 analogue, selectively binds with prostanoid receptors. Rectal, vaginal, sublingual, buccal and oral routes can be used to deliver it. ${ }^{3}$ Misoprostol has been found very useful for induction of labour and cervical ripening. ${ }^{12}$ It has longer half-life, noninvasive administration and maintains its stability at room temperature but have dose related shivering and pyrexia. ${ }^{5,13-15}$

These properties of misoprostol have gained pronounced attention towards it as an active substitute for postpartum hemorrhage prevention and management in under developed countries. However uterotonic effects of oxytocin versus misoprostol in reduction of blood loss have been found inconsistent in published studies. ${ }^{11,16,17}$ A study from Iran (2009) demonstrated that sublingual misoprostol at low dose (400ug) is more effective as compared to 20IU of oxytocin infusion. The blood loss was notably higher in the individuals treated with oxytocin than misoprostol $(673.9 \mathrm{ml}$ Vs $608.9 \mathrm{ml})$ respectively. Need for extra oxytocin treatment in the individuals treated with oxytocin was $36 \%$ while in misoprostol group was $14 \% .^{16}$

Another study from Nigeria (2011) showed that reduction in blood loss in group receiving misoprostol was significantly less than individuals receiving oxytocin (58.2 Vs $80.5 \mathrm{p}$-value $=0.02$ ). Harmful reactions like shivering and pyrexia was pronounced in individuals treated with misoprostol than the individuals treated with oxytocin $(25 / 50 \mathrm{Vs} 1 / 50 \mathrm{p}$-value $<0.001) .{ }^{11}$

Meta-analyses of randomized trials (2013) shows that misoprostol administered by sublingual or oral route as compared with injectable oxytocin by intravenous infusion may be equally effective in prevention of $\mathrm{PPH}$, but has more side effects like shivering, pyrexia but it is dose related. ${ }^{2}$

World Health Organization (WHO) recommends the use of 10 units of oxytocin as compared to misoprostol to avoid hemorrhage after delivery. ${ }^{18}$ Although many studies showed that misoprostol had advantageously been used to decrease the blood loss at caesarean section. ${ }^{11,16,17}$ So we decided to determine whether this low-priced and extensively used misoprostol is better to prevent hemorrhage at caesarean section than the oxytocin infusion, which is the drug of the choice in reduction of blood loss at caesarean section.

\section{METHODS}

Sample size of 82 patients, 41 patients in each group with $99 \%$ power of test, $3 \%$ level of significance, and taking expected mean value of misoprostol 58.2 and oxytocin as $80.5^{16}$ respectively.

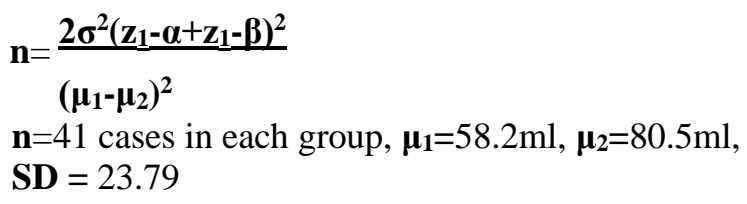

Non probability purposive sampling technique was used. All pregnant women with previous one caesarean section considered candidate for elective caesarean section after 37 completed weeks under spinal anesthesia. Women with placenta Previa, placental abruption, preeclampsia, eclampsia, over distended uterus due to polyhydramnios or multiple pregnancies. Women with history of previous major obstetric hemorrhage (>1000 $\mathrm{mL}$ ). Women receiving anticoagulant treatment. Pregnant women with known history of medical disorders (blood discariasis, renal, cardiovascular, respiratory and metabolic disorders like diabetes mellitus, hypertension, thyroid disorders). Grand multipara ( $>5$ pregnancies). Women with two or more caesarean sections. Women with history of rupture uterus.

The study was randomized controlled, single center, double blind trial of sublingual misoprostol versus intravenous oxytocin infusion for control of blood loss in women with singleton pregnancies at term who were scheduled for elective caeserean delivery at Lady Aitchison hospital under spinal anesthesia. Cases with placenta previa, placental abruption, pre-eclampsia, eclampsia, over distended uterus due to polyhydramnios or multiple pregnancies, women with history of previous major obstetric hemorrhage $(>1000 \mathrm{~mL})$, anticoagulant treatment, medical disorders (blood discariasis, renal, cardiovascular, respiratory and metabolic disorders like diabetes mellitus, hypertension, thyroid disorders), grand multipara ( $>5$ pregnancies), two or more caesarean sections and with history of rupture uterus were excluded from study. After approval from ethical committee and taking informed consent participants were randomly divided into two groups (A and B). Randomization was done by the help of Microsoft Excel 5.0 random number generator. The participants were randomly assigned to receive either misoprostol $400 \mu \mathrm{g}$ sublingually immediately at time of skin incision or intravenous infusion of 20 units of oxytocin in $1000 \mathrm{ml}$ saline solution that was started at time of cord clamping at rate of $10 \mathrm{ml} / \mathrm{min}$ for $30 \mathrm{mins}$ followed by $2 \mathrm{ml} / \mathrm{min}$ for $6 \mathrm{hrs}$. No stat dose of oxytocin was given in either group. Placenta was delivered by cord traction. When obstetrician noted poor uterine contraction, additional oxytocin was injected by anesthetist. After the procedure, obstetricians cleaned 
all participant's vagina with sterile gauzes $(4 \mathrm{x} 4$ gauze is 4 inches wide by 4 inches long $(10.16 \mathrm{~cm}$ by $10.16 \mathrm{~cm})$. The blood loss of all the participants was monitored for at least $2 \mathrm{hrs}$ post operatively. Blood loss was estimated separately by measuring the

- Blood volume in suction bottle

- Amniotic fluid volume was measured and subtracted

- Sponges, drapes and gauze pieces used for procedure were weighed preoperatively and post operatively.

- Blood clots retrieved were included in the blood loss estimation.

- Pads given to patients after surgery were weighed before and after use.

It was assumed that 1 gram increase in weight of pre weighed drapes, sponges and pads is equal to $1 \mathrm{ml}$. The balance in grams was equated to total blood loss in milliliters. ${ }^{20}$ Blood clots retrieved from vagina were collected in kidney dish and weighed. Post-operative blood loss was measured by doctor after first two hours of surgery. All these figures were noted on proforma, which was filled by researcher who calculated mean estimated blood loss. The main outcome measures were intraoperative blood loss and the need for additional uterotonic agents and postoperative hemoglobin $(\mathrm{Hb})$ fall. Secondary outcome measures were shivering, pyrexia, nausea, vomiting, operating time, postpartum hemorrhage, blood transfusion.

Data was tabulated and analyzed by SPSS version 17. The quantitative data (age, gestational age at time of delivery, calculated estimated blood loss, preoperative hemoglobin, postoperative hemoglobin on third day was presented in the form of mean $\pm S D$. Qualitative data type of anesthesia, indication for caesarean and type of caesarean section was given in frequency\%. Independent sample t-test was used to estimate mean blood loss in all treatment groups. If normality assumption is not fulfilled then Mamn-Withey U test was applied. Preoperative and postoperative hemoglobin was assessed with paired sample test. P-value $\leq 0.05$ was considered significant. Side effects of both treatment groups were compared by using chi-square test.

\section{RESULTS}

Table-1: There was no difference between the groups in age, duration of pregnancy

\begin{tabular}{lccc}
\hline Variable & Misoprostol & Oxytocin & p-value \\
\hline Age (years) & $25.76 \pm 3.48$ & $26.0 \pm 3.67$ & NS \\
$\begin{array}{l}\text { Gestational age } \\
\text { (weeks) }\end{array}$ & $39.73 \pm 1.32$ & $40.09 \pm 1.22$ & NS \\
\hline
\end{tabular}

There were significant differences in preoperative and postoperative $\mathrm{Hb}$ concentration as well as the amount of mean blood loss and need for additional uterotonic therapy between the two groups but need for blood transfusion was not statistically significant (Table 2 ).

Table 2.

\begin{tabular}{llll}
\hline Variable & Misoprostol & Oxytocin & $\mathrm{p}$-value \\
\hline $\begin{array}{l}\text { Preoperative } \\
\text { Hb(gldl) }\end{array}$ & $10.92 \pm 0.39$ & $11.03 \pm 0.34$ & 0.177 \\
$\begin{array}{l}\text { Postoperative } \\
\mathrm{Hb}(\mathrm{g} / \mathrm{dl})\end{array}$ & $10.38 \pm 0.42$ & $10.0 \pm 0.45$ & 0.000165 \\
$\begin{array}{l}\text { Mean estimated } \\
\text { blood loss (ml) }\end{array}$ & $612.68 \pm 20.97$ & $691 \pm 39.50$ & $<0.0001$ \\
$\begin{array}{l}\text { Need for additional } \\
\text { uterotonic therapy }\end{array}$ & $3(7.32 \%)$ & $25(60.98 \%)<0.001$ \\
$\begin{array}{l}\text { Need for blood } \\
\text { transfusion }\end{array}$ & $0(0 \%)$ & $4(9.76)$ & 0.065 \\
\hline
\end{tabular}

Comparison of the side effects revealed that shivering and pyrexia in misoprostol were significantly higher from the other group. While hypotension and vomiting were more in oxytocin group (Table 3 ).

Table 3

\begin{tabular}{|c|c|c|c|c|c|c|}
\hline & & \multicolumn{2}{|c|}{$\begin{array}{r}\text { Sublingual } \\
\text { Misoprostol }\end{array}$} & \multicolumn{2}{|c|}{ Oxytocin } & \multirow[t]{2}{*}{ p-value } \\
\hline & & $\mathrm{N}$ & $\%$ & $\mathrm{n}$ & $\%$ & \\
\hline \multirow[t]{2}{*}{ Nausea } & Yes & 5 & $12 \%$ & 20 & $49 \%$ & \multirow{2}{*}{0.00032} \\
\hline & No & 36 & $88 \%$ & 21 & $51 \%$ & \\
\hline \multirow[t]{2}{*}{ Vomiting } & Yes & 0 & $0 \%$ & 12 & $29 \%$ & \multirow{2}{*}{0.00029} \\
\hline & No & 41 & $100 \%$ & 29 & $71 \%$ & \\
\hline \multirow{2}{*}{$\begin{array}{l}\text { Hypo } \\
\text { tension }\end{array}$} & Yes & 0 & $0 \%$ & 20 & $49 \%$ & \multirow{2}{*}{$<0.001$} \\
\hline & No & 41 & $100 \%$ & 21 & $51 \%$ & \\
\hline \multirow[t]{2}{*}{ Pyrexia } & Yes & 15 & $37 \%$ & 3 & $7 \%$ & \multirow{2}{*}{0.00136} \\
\hline & No & 26 & $63 \%$ & 38 & $93 \%$ & \\
\hline \multirow[t]{2}{*}{ Shivering } & Yes & 22 & $54 \%$ & 2 & $5 \%$ & \multirow{2}{*}{$<0.001$} \\
\hline & No & 19 & $46 \%$ & 39 & $95 \%$ & \\
\hline
\end{tabular}

In the Misoprostol group mean $\mathrm{Hb}$ on third postoperative day was $10.38 \pm 0.42 \mathrm{~g} / \mathrm{dl}$ while the minimum $\mathrm{Hb}$ on third postoperative day was $9.2 \mathrm{~g} / \mathrm{dl}$ and maximum $\mathrm{Hb}$ on third postoperative day was $11.0 \mathrm{~g} / \mathrm{dl}$. While in Oxytocin group the mean $\mathrm{Hb}$ on third postoperative day was $10.0 \pm 0.45 \mathrm{~g} / \mathrm{dl}$. Minimum $\mathrm{Hb}$ on third postoperative day was $9.0 \mathrm{~g} / \mathrm{dl}$ and maximum $\mathrm{Hb}$ on third postoperative day was $10.9 \mathrm{~g} / \mathrm{dl}$. Pre operatively mean $\mathrm{Hb}$ level was statistically same in both group but post operatively mean $\mathrm{Hb}$ level was significantly dropped in oxytocin group. i.e. $\mathrm{p}$-value $=0.000165$. Mean blood loss was significantly higher in oxytocin group as that of Misoprostol. i.e. pvalue $<0.001$.

\section{DISCUSSION}

Death due to pregnancy remains an important cause of premature mortality of women worldwide, estimating 
500,000 women die per year and a quarter of them occurs because of hemorrhage. In developed and as well as under developed countries $1-5 \%$ of the deliveries can lead into post-partum hemorrhage, which is one of the most common cause of maternal morbidity and mortality. ${ }^{18}$

Simply stating, post-partum hemorrhage is an equal opportunistic killer and no patient is immune from it, as it is evidently accepted that its occurrence is unpredictable. Earlier studies showed that oxytocin is more effective than oral misoprostol because misoprostol has slower onset of action. ${ }^{19}$

In this study Sublingual misoprostol was compared with IV oxytocin infusion to control blood loss at caesarean section. The patients who were given sublingual misoprostol showed considerably less mean estimated blood loss as compared to those patients who were given IV oxytocin infusion, i.e. $612.68 \mathrm{ml}$ vs. $691.71 \mathrm{ml}$, pvalue $=0.0001$. Additional uterotonic therapy was required in oxytocin group for $25(60.98 \%)$ patients however in Sublingual misoprostol group only $3(7.32 \%)$ patients required additional uterotonic therapy. MB Bellad in this study reported that the mean blood loss in women who received 400ug sublingual misoprostol was $192 \pm 124 \mathrm{ml}$, compared with the blood loss of $366 \pm 136 \mathrm{ml}$ in women receiving intramuscular oxytocin for the prevention of $\mathrm{PPH} .{ }^{20}$ Results of this study regarding blood loss were consistent with the results reported by MB Bellad. The Cochrane Review found no significant difference in mean scores of blood loss between sublingual misoprostol and injectable uterotonics, and no difference in prevention of PPH through these drugs. ${ }^{4}$ However, the review combines different doses of misoprostol (50ug, 35 400ug, and 600ug) and injectable uterotonics (ergometrine, syntometrine, and oxytocin) with variable doses and discrete effectiveness. In our study post-operative hemoglobin was decreased by $-4.95 \%$ in sublingual misoprostol (Pre: 10.92 \& Post: 10.38 ) and in oxytocin group post-operative hemoglobin was decreased by $-9.33 \%$ (Pre: 11.03 \& Post: 10.00). Chaudhuri et al. and Mobeen et al. did not find any considerable change in $\mathrm{Hb} .{ }^{21}$ In the study by Bellad et al. it was noted that there was significantly less drop in postpartum $\mathrm{Hb}$ in misoprostol group as compared to oxytocin group. ${ }^{20} \mathrm{MB}$ Bellad study detected that hemoglobin drop $>10 \%$ in $45.6 \%$ women who received oxytocin as compared to misoprostol group in which hemoglobin drop was noted only in $9.7 \%$ women. ${ }^{20}$

Results of this study regarding additional uterotonic therapy showed that in women who were given sublingual misoprostol, among them $3(7.32 \%)$ women required additional uterotonic therapy. However, in oxytocin group $25(60.98 \%)$ women need additional uterotonic therapy. Need of uterotonic therapy is significantly high in oxytocin group. i.e. (p-value $=0.001$ ).

Priya in her study reported that two cases in misoprostol group and three cases in oxytocin group required additional oxytocin because of uterine atony. ${ }^{22}$ Chaudhuri et al., in his study reported no statistical significance in the requirement of additional oxytocin in between the two groups in both the studies. ${ }^{21}$ In Bellad et al. study, one case in misoprostol group required additional oxytocin whereas 8 cases in oxytocin group which was statistically significant $(\mathrm{p}=0.002){ }^{20}$

In the study of Elati et al., high risk cases were not included, so none of them required additional oxytocin as none of the group bleed more than $500 \mathrm{ml} .{ }^{13}$ According to El-Refaey et al. study he had to use additional oxytocin for 9 cases of misoprostol group and for 11 cases of oxytocin group. ${ }^{23} \mathrm{MB}$ Bellad in his study stated that six of the women from oxytocin group required additional oxytocin, on the other hand not even a single case from misoprostol group required oxytocin to treat $\mathrm{PPH}$ (additional uterotonics, $\mathrm{P}=0.001) .{ }^{20}$

Few studies have reported the additional need of uterotonic therapy for oxytocin as well as for sublingual misoprostol but in this study sublingual misoprostol group required no additional uterotonic therapy. ${ }^{21}$ Bellad et al. described only a single event of retention of placenta in woman receiving oxytocin and in both groups blood was transfused to one women. That was a statistically insignificant. ${ }^{20}$ In El-Refaey study he stated that blood transfusion was done in 9 women in misoprostol as compare to the 11 cases from oxytocic group. ${ }^{23}$ A Elati in his study reported that neither blood transfusion nor additional uterotonics were required in women who were injected with oxytocin intramuscularly or sublingual misoprostol. ${ }^{13}$ Beverly Winikoff in his study reported a significant blood transfusion rate as $8 \%$ for misoprostol group and $5 \%$ for oxytocin. ${ }^{24}$

In this study it was observed that women who were given sublingual misoprostol they did not require blood transfusion however women who were given oxytocin among them 4(9.76\%) required blood transfusion. As per these findings blood transfusion was statistically lower in sublingual misoprostol and these results are same as described by Beverly Winikoff. ${ }^{24}$

Side effect profile of sublingual misoprostol showed that incidence of shivering was $54 \%$ followed by pyrexia $(37 \%)$ and nausea (12\%). So shivering was most common side effect of misoprostol. In oxytocin group the incidence of side effects was nausea (49\%) and hypotension (49\%) followed by vomiting pyrexia (7\%) and shivering (5\%). Nausea, vomiting and hypotension were considerably more in oxytocin group. i.e. (Nausea: $12 \%$ vs. $49 \%$, pvalue $=0.0032$, Vomiting: $0 \%$ vs. $29 \%$, p-value $=0.0029 \&$ Hypotension: $0 \%$ vs. $49 \%$, p-value $=0.001$ ). Conversely pyrexia and shivering were considerably more in misoprostol group. (Pyrexia: $37 \%$ vs. 7\%, pvalue $=0.0013$, Shivering: $54 \%$ vs. $5 \%$, p-value $=0.001$ ).

We found increased rates of side effects with misoprostol versus oxytocin, as has been previously 
reported. ${ }^{25}$ Although misoprostol-related shivering is typically considered a nonserious side effect, prior studies have reported fever, ${ }^{26,27}$ secondary psychological effects including anxiety, and perceptions of lack of body control. ${ }^{28}$ The difference of nausea and vomiting in the two groups was significant.

MB Bellad study showed that side effects were less in oxytocin group than misoprostol group. ${ }^{20}$ Mariana Widmer also reported a high frequency of shivering in women who were given misoprostol. ${ }^{29}$ In this study 54\% of the women had shivering who were given misoprostol. Al-Sawaf noted that shivering that occurred after oxytocin administration may be linked to its hemodynamic actions that causes shivering. In this favor, tachycardia was observed in women receiving oxytocin. ${ }^{30}$ Oxytocin effects blood pressure and heart rate through these mediators, nitric oxide, atrial natriuretic peptide and alpha2-adrenoreceptors. ${ }^{31}$

In this study about $49 \%$ of the women suffered from hypotension who were given oxytocin. However, in misoprostol group none of the women experienced hypotension.

Beverly Winikoff also reported that Shivering (229 [47\%] vs 82 [17\%]; RR 2.80, 95\% CI 2.25-3.49) and fever (217 [44\%] vs27 [6\%]; 8.07, 5.52-11.8) were considerably more in misoprostol group as compare to the oxytocin group ${ }^{24}$ Similar findings were also reported by Jennifer Blum Shivering (152 [37\%] vs59 [15\%]; RR $2.54,95 \%$ CI 1.95-3.32) and fever (88 [22\%] vs59 [15\%]; $1.47,1.09-1.99)$ were considerably more common with misoprostol as compare to oxytocin. ${ }^{32}$

\section{CONCLUSION}

Results of this trial showed that sublingual misoprostol is more effective as compared to intravenous oxytocin infusion in terms of reduction of blood loss in first two hours at caesarean section and is superior to oxytocin. Though the side effects like fever and shivering occur more with misoprostol than oxytocin but they occur only transiently and are self-limiting.

\section{ETHICAL APPROVAL}

The study was approved from Institutional Review Board of King Edward Medical University, Lahore, Pakistan, vide reference No. 95/RC/KEMU, dated August 30, 2014.

\section{REFERENCES}

1. Mobeen N, Durocher J, Zuberi N, Jahan N, Blum J, Wasim S, et al. Administration of misoprostol by trained traditional birth attendants to prevent postpartum hemorrhage in homebirths in Pakistan: a randomised placebo-controlled trial. BJOG: An International Journal of Obstetrics \& Gynaecology. 2011;118(3):353-361.
2. Hua J, Chen G, Xing F, Scott M, Li Q. Effect of misoprostol versus oxytocin during caesarean section: a systematic review and meta-analysis. BJOG: An International Journal of Obstetrics \& Gynaecology. 2013;120(5):531-540.

3. Cunningham FG, Leveno KJ, Bloom SL, Hauth J, Gilstrap L, Wenstrom K. Williams obstetrics. 23nd. NewYork: McGRAW Hill Medical Publishing Division. 2010;35:575-803.

4. Gülmezoglu AM, Forna F, Villar J, Hofmeyr GJ. Prostaglandins for preventing postpartum hemorrhage. Cochrane Database Syst Rev. 2007;3(3).

5. Hofmeyr GJ, Gülmezoglu AM, Novikova N, Linder V, Ferreira S, Piaggio G. Misoprostol to prevent and treat postpartum hemorrhage: a systematic review and metaanalysis of maternal deaths and dose-related effects. Bulletin of the World Health Organization. 2009;87(9):666-677.

6. Nirmala K, Zainuddin AA, Ghani NAA, Zulkifli S, Jamil MA. Carbetocin versus syntometrine in prevention of post-partum hemorrhage following vaginal delivery. Journal of Obstetrics and Gynaecology Research. 2009;35(1):48-54.

7. Matsubara S, Yano H, Taneichi A, Suzuki M. Uterine compression suture against impending recurrence of uterine inversion immediately after laparotomy repositioning. Journal of Obstetrics and Gynaecology Research. 2009;35(4):819-823.

8. Soltan MH, Faragallah MF, Mosabah MH, Al-adawy AR. External aortic compression device: the first aid for postpartum hemorrhage control. Journal of Obstetrics and Gynaecology Research. 2009;35(3):453-458.

9. Meydanli MM, Türkçüoğlu I, Engin-Üstün Y, Üstün Y, Kafkasli A. Meydanli compression suture: new surgical procedure for postpartum hemorrhage due to uterine atony associated with abnormal placental adherence. Journal of Obstetrics and Gynaecology Research. 2008;34(6):964-970.

10. Nohira T OY, Suda S. Successful management b recombinant activated factor VII in case of DIC caused by obstetric hemorrhage. J Obstet Gynaecol Res. 2008;34:623-630.

11. Owonikoko KM, Arowojolu AO, Okunlola MA. Effect of sublingual misoprostol versus intravenous oxytocin on reducing blood loss at caesarean section in Nigeria: a randomized controlled trial. Journal of Obstetrics and Gynaecology Research. 2011;37(7):715-721.

12. Carroli G, Cuesta C, Abalos E, Gulmezoglu AM. Epidemiology of postpartum hemorrhage: a systematic review. Best practice \& research Clinical obstetrics \& gynaecology. 2008;22(6):999-1012.

13. Elati A, Elmahaishi M, Elmahaishi M, Elsraiti O, Weeks A. The effect of misoprostol on postpartum contractions: a randomised comparison of three sublingual doses. BJOG: An International Journal of Obstetrics \& Gynaecology. 2011;118(4):466-473. 
14. Anbreen F. Efficacy of Rectal Misorpostol when Combined with Standard Oxytocin to Treat Postpartum Hemorrhage. Gomal Journal of Medical Sciences. 2010;8(1).

15. Mansouri H, Alsahly N. Rectal versus oral misoprostol for active management of third stage of labor: a randomized controlled trial. Archives of gynecology and obstetrics. 2011;283(5):935-939.

16. Eftekhari N, Doroodian M, Lashkarizadeh R. The effect of sublingual misoprostol versus intravenous oxytocin in reducing bleeding after caesarean section. Journal of Obstetrics \& Gynaecology. 2009;29(7):633-636.

17. Chaudhuri P, Banerjee GB, Mandal A. Rectally administered misoprostol versus intravenous oxytocin infusion during caesarean delivery to reduce intraoperative and postoperative blood loss. International Journal of Gynecology \& Obstetrics. 2010;109(1):25-29.

18. Knight $\mathrm{M}$, Callaghan WM, Berg C, Alexander S, Bouvier-Colle M-H, Ford JB, et al. Trends in postpartum hemorrhage in high resource countries: a review and recommendations from the International Postpartum Hemorrhage Collaborative Group. BMC pregnancy and childbirth. 2009;9(1):55.

19. Gülmezoglu AM, Villar J, Ngoc NTN, Piaggio G, Carroli G, Adetoro L, et al. WHO multicentre randomised trial of misoprostol in the management of the third stage of labour. The Lancet. 2001;358(9283):689-695.

20. Bellad M, Tara D, Ganachari M, Mallapur M, Goudar S, Kodkany B, et al. Prevention of postpartum hemorrhage with sublingual misoprostol or oxytocin: a double-blind randomised controlled trial. BJOG: An International Journal of Obstetrics \& Gynaecology. 2012;119(8):975-986.

21. Chaudhuri P, Biswas J, Mandal A. Sublingual misoprostol versus intramuscular oxytocin for prevention of postpartum hemorrhage in low-risk women. International Journal of Gynecology \& Obstetrics. 2012;116(2):138-142.

22. Priya GP, Veena P, Chaturvedula L, Subitha L. A randomized controlled trial of sublingual misoprostol and intramuscular oxytocin for prevention of postpartum hemorrhage. Archives of gynecology and obstetrics. 2015:1-7.

23. El-Refaey H, Nooh R, O'Brien P, Abdalla M, Geary M, Walder J, et al. The misoprostol third stage of labour study: a randomised controlled comparison between orally administered misoprostol and standard management. BJOG: An International Journal of Obstetrics \& Gynaecology. 2000;107(9):1104-1110.
24. Winikoff B, Dabash R, Durocher J, Darwish E, Ngoc NTN, León W, et al. Treatment of post-partum hemorrhage with sublingual misoprostol versus oxytocin in women not exposed to oxytocin during labour: a double-blind, randomised, non-inferiority trial. The Lancet. 2010;375(9710):210-216.

25. Tunçalp Ö, Hofmeyr GJ, Gülmezoglu AM. Prostaglandins for preventing postpartum hemorrhage. Cochrane Database Syst Rev. 2012;8(8):CD000494.

26. Durocher J, Bynum J, León W, Barrera G, Winikoff B. High fever following postpartum administration of sublingual misoprostol. BJOG: An International Journal of Obstetrics \& Gynaecology. 2010; 117(7):845-852.

27. Elati A, Weeks A. Risk of fever after misoprostol for the prevention of postpartum hemorrhage: a meta-analysis. Obstetrics \& Gynecology. 2012;120(5):1140-1148.

28. Amant F. The misoprostal third stage study: a randomsed controlled comparison between orally administreted misoprostol and standard management $\mathrm{A}$ double-blind placebo controlled randomised trial of misoprostol and oxytocin in the management of the third stage labour. British Journal of Obstetrics and Gynaecology. 2001;108(3):338.

29. Widmer M, Blum J, Hofmeyr GJ, Carroli G, Abdel-Aleem H, Lumbiganon $\mathrm{P}$, et al. Misoprostol as an adjunct to standard uterotonics for treatment of post-partum hemorrhage: a multicentre, double-blind randomised trial. The Lancet. 2010;375(9728):1808-1813.

30. Al-Sawaf A, El-Mazny A, Shohayeb A. A randomised controlled trial of sublingual misoprostol and intramuscular oxytocin for prevention of postpartum hemorrhage. Journal of Obstetrics \& Gynaecology. 2013;33(3):277-279.

31. Petersson M. Cardiovascular effects of oxytocin. Progress in brain research. 2002;139:281-288.

32. Blum J, Winikoff B, Raghavan S, Dabash R, Ramadan MC, Dilbaz B, et al. Treatment of post-partum hemorrhage with sublingual misoprostol versus oxytocin in women receiving prophylactic oxytocin: a double-blind, randomised, non-inferiority trial. The Lancet. 2010;375(9710):217-223.

\section{AUTHOURS CONTRIBUTIONS}

MJ, MI: Concept, Design, Manuscript writing Data collection, Data analysis 